\title{
WHAT INFLUENCES FAMILY PLANNING IN RURAL PAKISTAN: FRANCHISED SERVICE PROVIDER AND COMMUNITY HEALTH WORKER PERSPECTIVE
}

\author{
Waqas Hameed ${ }^{1}$, Junaid-ur-Rehman Siddiqui ${ }^{2}$, Muhammad Ishaque ${ }^{3}$, Sharmeen Hussain ${ }^{4}$, Xaher Gul $^{5}$, \\ Hina Najmi ${ }^{6}$, Shehla Noorani ${ }^{7}$, Ghulam Mustafa $^{8}$, Asma Balal ${ }^{9}$
}

${ }^{1}$ Waqas Hameed, General Manager Programme Design and Development,Marie Stopes Society

${ }^{2} J u n a i d-u r-R e h m a n$ Siddiqui, Programme Design and Development Executive,Marie Stopes Society

${ }^{3}$ Muhammad Ishaque, Manager Research \& Evaluation, Marie Stopes Society

${ }^{4}$ Sharmeen Hussain, Deputy Senior Manager Behaviour Change Communication, Marie Stopes Society

${ }^{5}$ Xaher Gul, Director Strategy, Marie Stopes Society

${ }^{6}$ Hina Najmi, Manager Behaviour Change Communication, Marie Stopes Society

${ }^{7}$ Shehla Noorani, Assistant Manager Technical Services, Marie Stopes Society

${ }^{8}$ Ghulam Mustafa, Deputy Senior Manager Research Monitoring and Evaluation, Marie Stopes Society

${ }^{9}$ Asma Balal, Country Director, Marie Stopes Society

Correspondence: Junaid-Ur-Rehman Siddiqui. Email: junaidrehman1994@hotmail.com

\begin{abstract}
Background: Pakistan has a low modern contraceptive prevalence rate, 26\%, leading family planning (FP) programmes to explore partnerships with local private providers to improve access to quality FP services. This study aims to understand the socio-cultural and organizational factors that influence delivery of quality family planning services.

Methods: This qualitative study was conducted with private service providers and community health workers (CHW) in Marie Stopes Society's (MSS) social franchise network. A total of 31 providers and 28 CHWs from Sindh, Punjab, and Khyber Pakhtunkhwa provinces of Pakistan were purposively selected for in-depth interviews. The study used thematic content analysis to understand providers' and health workers' perspectives of family planning service provision.

Results: This study found that normative environment, propagation of myths and misconceptions, and health concerns remain major barriers to service provision in rural communities. Findings showed that $\mathrm{CHWs}$ were instrumental in increasing awareness and positive attitudes towards family planning in the catchment areas. Moreover, social franchising was effective in increasing access to high-quality, subsidised family planning services amongst economically marginalised and low-awareness communities. Providers and health workers expressed satisfaction with the franchising approach, and revealed that being part of this network substantially increased their client volume and ability to serve poorer segments of the population.

Conclusion: The study found that franchising private service providers in rural areas enhances their ability to serve clients, and when coupled with demand-generation elements, such as vouchers and community health workers, it substantially increases their client volume. Albeit effective, the franchising approach currently lacks the element of long-term service provision at the current scale, and may require further strategizing by the franchisor. Moreover, alternate strategies should be explored to ensure continued provision of FP services without vouchers and CHWs.

Keywords: Social franchise, vouchers, community health workers, family planning, in-depth interviews, rural, pakistan, qualitative study, modern contraception, contraceptives
\end{abstract}

\section{Introduction}

Pakistan is facing the daunting challenge of rapid population growth; and with an annual growth rate of $2.4 \%$, the country's population is growing faster than its South Asian neighbours $(1,2)$. Pakistan is among the few countries in the region that launched a national family planning programme in the $1960 \mathrm{~s}$, but, to date, the programme has yielded lukewarm results (1).

The country signed the Family Planning 2020 pledge to control population growth by increasing the national contraceptive prevalence rate (CPR) from $35 \%$ to $50 \%$ by 2020 (3). However, the increase in CPR per annum since 2006-07 has been less than one percent. The Pakistan Demographic and Health Survey of 2012-13 found low use of modern contraception (26.1\%),a high unmet need for family planning (20\%).and that use of modern contraception has a strong relationship with wealth, education and geographical residence (1). 
The dearth of health workers is a major barrier in improving access to family planning and reproductive health (FP/RH) services, especially among the economically, socially, and geographically marginalised populations (5). World Health Organization (WHO) recommended the engagement of private sector providers to expand coverage of healthcare services (6), and in the last decade, social franchising has emerged as an increasingly popular approach to deliver qualityassured family planning services in developing countries (7). Embedment of voucher schemes in family planning programmes, especially social franchising programmes, has been advocated as an effective approach to promote $\mathrm{FP} / \mathrm{RH}$ services in areas with limited health resources (8-10).

In Pakistan, an increasing number of family planning programmes are using social franchising to increase access to and affordability of $\mathrm{FP} / \mathrm{RH}$ services in periurban and rural areas (11). However, the ability of a franchised provider to deliver high-quality services varies with the providers' FP knowledge, attitudes, beliefs, values, and their perception of quality of care $(12,13)$. Moreover, organizational factors such as provision of supplies and equipment, infrastructure, workload, and providers' normative environment also constrict their ability to deliver quality services $(12,14,15)$. Multiple studies have demonstrated the significant impact of social franchising when integrated with vouchers on contraceptive uptake $(16,17)$ and continuation $(18,19)$ in Pakistan, however, there is very little evidence that looks into the operational details of social franchising(19) or captures the perspectives of franchisees and community health workers associated with the network. Therefore, to understand the sociocultural and organizational factors that influence the delivery of quality family planning services, we conducted an explanatory qualitative study with a group of franchised providers and CHWs in the network.

Marie Stopes Society's Social Franchise Programme

The Marie Stopes Society (MSS) social franchise programme aims to increase demand, access, and choices for quality $\mathrm{FP} / \mathrm{RH}$ services to the underserved and poor communities across Pakistan. The network is comprised of more than 450 franchised service providers in rural and far-flung areas of Sindh, Punjab, and Khyber Pakhtunkhwa and is based on a twopronged approach whereby programme efforts target both supply and demand side barriers (11). MSS utilizes a network of community health workers (CHWs) who conduct household visits and distribute family planning service vouchers to marginalized women in their catchment areas to increase demand while tackling supply side barriers by conducting business and clinical trainings for providers and ensuring a consistent supply of FP commodities for their centres.

\section{Methodology}

Study design and setting

Using an explanatory qualitative design, in-depth interview (IDI) methodology was employed for data collection. Owing to saturation of information and minimum representation from all geographical areas, a total of 59 IDIs were conducted: 27 with Suraj providers, 28 with $\mathrm{CHWCHWs}$, and four with drop-out Suraj providers in 24 districts of Sindh, Khyber Pakhtunkhwa, and Punjab provinces.

\section{Study population and sampling}

The study was conducted among MSS Suraj Social Franchise private-sector service providers and their respective community health worker and service providers who had dropped-out from the franchise network. The sample was purposively selected based on results of routine service delivery data analysis (e.g. providers that had high client volume, providers that had low client volume, providers that had high quality assurance (QA) scores, and providers that had low QA scores). The distribution of sample by province is presented in Table 1 below.

Table 1: District of study participants by province

\begin{tabular}{|c|c|c|c|c|}
\hline Province & Districts & $\begin{array}{l}\text { Service } \\
\text { provider }\end{array}$ & $\begin{array}{c}\text { Community } \\
\text { health } \\
\text { worker }\end{array}$ & $\begin{array}{c}\text { Drop-out } \\
\text { service } \\
\text { provider }\end{array}$ \\
\hline Sindh & $\begin{array}{l}\text { Naushero Feroze, Jacobabad, } \\
\text { Kamber, Karachi, Khairpur, Larkana, } \\
\text { Mirpurkhas, Q.S.Kot, Shikarpur, } \\
\text { Sukker, Tando Allahyar }\end{array}$ & 14 & 17 & 3 \\
\hline Punjab & $\begin{array}{l}\text { Bahawalnagar, Bahawalpur, Lahore, } \\
\text { Multan, Muzaffargarh, Rahim Yar } \\
\text { Khan, Rajanpur, Sialkot, Toba Tek } \\
\text { Singh, Vehari }\end{array}$ & 10 & 7 & 1 \\
\hline $\begin{array}{l}\text { Khyber } \\
\text { Pakhtunkhwa }\end{array}$ & Haripur, Mardan, Peshawar & 3 & 4 & 0 \\
\hline Total & & 27 & 28 & 4 \\
\hline
\end{tabular}

Interview tool and pre-test

Individualised semi-structured interview tools were developed for each type of study participant. Besides general information on study participants, the key thematic areas broadly covered in the interview guide were: a) general perceptions and practices about family planning; b) performance of franchise providers and reasons for inconsistent trends in contraceptive services; c) quality of care; d) use of vouchers, their management, and how community- and organizationallevel factors affect their utilization; and e) sustainability prospects of the social franchise programme. The interview guides were originally developed in English and later translated to the local language (Urdu). The tools were pre-tested in the field and required modifications were incorporated into the tools before commencement of data collection. This was done by 
researchers to ensure that the tools were culturally appropriate and that the language was easily understood by the study participants.

\section{Data collection and management}

Interviews were conducted from June-July 2015 by a trained anthropologist and a sociologist who had prior experience in the field of family planning. Interviews with service providers were carried out at their health facilities whereas field workers were interviewed either at their homes or MSS district offices in complete privacy. Each interview took approximately 45-60 minutes.

\section{Data analysis}

All of the audio-recorded interviews were transcribed verbatim and translated into English. A team of three qualitative researchers carried out the data analysis. Data analysis was conducted manually and was guided by thematic content analysis. Transcripts were read several times to develop themes and new codes based on the actual words of the study participants. Data analysis was conducted by the research team, based on three types of coding: sub themes, themes, and categories. The identified codes, themes, and patterns were reviewed alternately by each researcher to minimize bias and to ensure reliability.

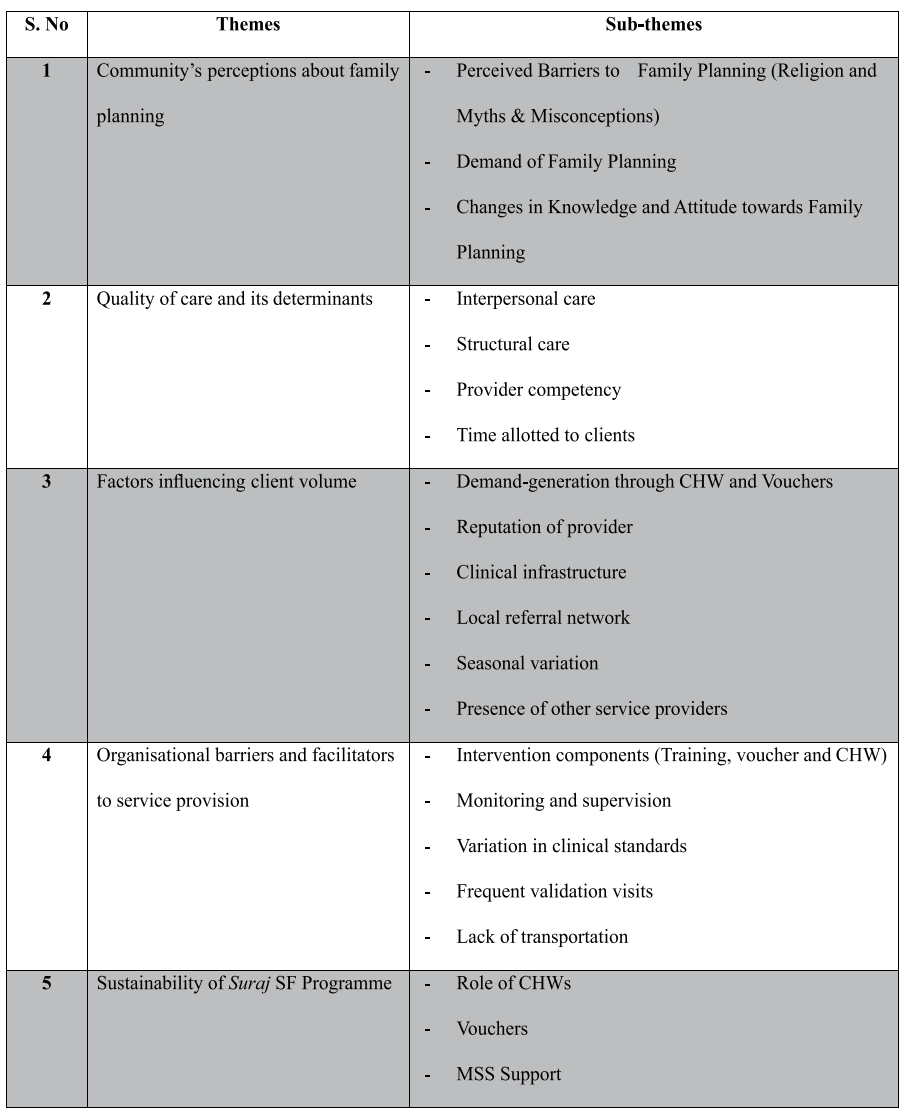

\section{Ethics}

Preserving the dignity, rights, and safety of participants was a primary concern for this research study. Informed consent was taken from all participants. The study protocol was reviewed and approved by Research Ethics Committee of National Bioethics Committee (Ref:
No. 4-87/15/NBC-183/RDC/1077).

\section{Results}

Community's Perceptions about Family Planning

Almost all participants believed that generally, poor people, especially those living in the rural areas, are in greater need of family planning (FP) services. Lack of FP awareness and low contraceptive use has resulted in high fertility rates, which when combined with financial constraints, leads to poor maternal and reproductive health in the community.

"In cities, people are educated and know how to manage their families. But in villages people don't know about family planning; they need information and counselling. In the village, family planning is more necessary."

CHW, Mirpur Khas, Sindh

"Family planning is necessary, especially for the poor people. They have less earnings and can't support large families. Poor women here also work at homes as maids, and are not healthy enough to have more children so they need family planning."

Service Provider, Lahore, Punjab

According to the participants, family planning is perceived as a means to limit fertility which is deemed sinful and un-Islamic. Service providers and community health workers stressed that family planning be promoted as a means to space births to improve the health of mothers and children.

"There are a lot of religious issues (regarding FP). There are many maulvis (religious clerics) who tell us that we are reducing the population of Pakistani children. They even abuse at us, but we say that it is not a sin".

CHW, Tando Allahyar, Sindh

"We explain to our clients that we are not asking them to have only 1-2 children, but we are encouraging them to wait for at least 2-3 years, before planning another child for the sake of mother's and child's health.

CHW, Haripur, Khyber Pakhtunkhwa

Moreover, the majority of the participants believed that there were serious myths and misconceptions regarding FP among women, particularly about IUCDs.

"Some (women) say IUCD will burst inside and will cause cancer. Now, with time, we are guiding them, and with training, we are trying to convince them in an effective manner."

Service Provider, Lahore, Punjab

However, CHWs and service providers have observed a positive change in the knowledge and attitude towards family planning over time, which was primarily attributed to FP awareness, good counselling, and community mobilization work by $\mathrm{CHWs}$.

"Now, people think positively about family planning. Since I have been providing family planning services, women have started relying on me for receiving family planning methods"

Service Provider, Sialkot, Punjab

Quality of Care and its Determinants

The majority of the service providers believed that interpersonal communication is the most important 
aspect of quality of care, for example - good counselling with friendly and respectful behaviour towards clients. In addition, adequate and clean clinical infrastructure, availability of FP methods of choice, qualified staff, and regular follow-up are also considered important determinants of quality.

"The most important thing is your behaviour. The provider should also inspire confidence in the clients. She should keep the information of clients confidential. Clients should have trust in the provider. Provider should also be caring."

Service Provider, Vehari, Punjab

"A good clinic should be clean, instruments should be sterilized, and its provider should wear gloves while conducting a medical check-up. Trash from the clinic should be dumped outside properly."

Suraj Provider, Bahawalpur, Punjab

On the other hand, some CHWs highlighted that impolite behaviour of providers and insufficient time spent with clients can lead to client dissatisfaction.

"There have been issues (where a client did not receive proper care). There must be proper care for the clients and time must be given to them. This is not just about giving them an injection and then asking them to go."

CHW, Qamber Shahdad Kot, Sindh

\section{Factors Influencing Client Volume}

Study participants reported a number of factors that play an important role in the increasing and decreasing client flow at Suraj centres.

According to service providers, the most important factor influencing client volume were proactive and motivated CHWs and free FP vouchers. In addition, good reputation of service providers, provision of quality services, and cleanliness of clinic also attract more clients to Suraj centres.

"Our good performance mostly depends upon CHW's role and work. If CHWs are not doing their job properly then our number of clients will decrease."

Service Provider, Lahore, Punjab

"When people hear about free service they come to us. People are poor and are affected by floods every year. People cannot afford other doctors who take PKR 100 (Approximately \$1) from them. Hence, they come to us forfree services."

Service Provider, Kamber Shahdad Kot-Sindh

While keeping an emphasis on the quality of care, community health workers also identified good relationships with other health workers (such as lady health workers and traditional birth attendants) as an important factor for increased client flow at Suraj franchises.

"LHVs are our friends and refer clients to us. We also remain in touch with midwives (for client referral), and have our own personal relations as well."

CHW, Kamber, Sindh

Additionally, study participants identified some factors that negatively affect client flow at the Suraj centres. These included seasonal variations: crop harvesting and sowing season, absence/drop-out of CHWs, presence of other healthcare facilities, and low acceptability of family planning among certain communities and villages.

"In the crops (harvesting or sowing) season, the women tell us that in this season they cannot use FP methods because in this season they work and earn their livelihood so they cannot come to clinics. That is why there is a decrease in clients during these seasons."

CHW, Sindh

"There is difference of area also. There are some areas that if you go there once and pursue them they come and in some areas, you have to go 2-3 time then they come with difficulty."

Service Provider, Punjab

"There are many civil hospitals here so more clients go to them. The LHW of national program has been working here for fifteen years."

Service Provider, Tando Allahyar, Sindh

Organisational Barriers and Facilitators to Service Provision

Being a part of the Suraj network was seen as the key facilitator to service provision. Service providers believed that enhanced capacity through trainings by MSS on quality of care and service provision have enabled them to provide quality-assured and infection free services. Further, timely provision of contraceptive supplies by MSS was seen as an essential facilitator to service provision by providers. Most providers and community health workers expressed satisfaction with monitoring and supervisory visits conducted by MSS, and were of the view that such activities gave them feedback about their work, and help them to improve their performance.

"Trainings greatly increased our clients as we successfully provided quality services and spread our message about family planning among women."

Service Provider, Lahore, Punjab

"MSS support to us was quite good. They always provide stock on time and whatever was requested was provided to us on time."

Service Provider, Haripur, KhyberPakhtunkhwa

"Monitoring visits are beneficial and give us feedback about ourselves. They help us (to improve) if in case anything is being done wrong or anything related to worker or clients is wrong. They discuss such things with us."

CHW, Mardan, Khyber Pakhtunkhwa

Most of the providers expressed satisfaction with various of being a franchisee, however, there were some providers underscored some barriers in this regard, and discussed that trainings should be need-based and planned more efficiently to avoid repetition. Lack of adequate equipment (sterilizers for instance) and changes in clinical standards were also cited as issues by these providers.

"Trainings are usually good, but I think the number is too high. I think we do not require as much trainings as they 
are offering. If there is a new method then trainings should be given but we do not need trainings on things we know already."

Services Provider, Tando Allahyar, Sindh

"At every visit, teams give us some new instructions (relating to clinical standards). There is no long-term uniform policy and this creates problems for service providers."

Service Provider, Bahawalnangar, Punjab

The CHWs highlighted that the absence of transport facilities and limited travel allowances make it very difficult for them to visit houses in far-flung areas. Frequent validation visits were reported as a common concern from all study participants.

"During field visits, we face problems in commuting and travelling in far off villages. For example, we get transport at a certain time and we reach field by 6:00 in morning so we cannot visit homes at that time as it is very early so we have to wait till 8-9AM to start field work."

CHW, Haripur, Khyber Pakhtunkhwa

"Frequent validation (of vouchers) is an issue and embarrasses our clients."

CHW, Mardan, Khyber Pakhtunkhwa

\section{Sustainability of the Suraj SF Programme}

Almost all of the participants felt that it would be difficult to sustain the SF programme without the $\mathrm{CHW}$ and the voucher component. They stated that client flow will decrease drastically in the absence of these components, and that withdrawal of vouchers would adversely affect non-paying clients. Conversely, given the importance of the CHWs' role, some providers (whose client flow had drastically improved since the induction of $\mathrm{CHWs}$ ) suggested that providers can keep the CHWs when organizational support is withdrawn following a pay for performance arrangement.

"Sustainability without MSS support seems very difficult. I will not be able to continue without the support of $\mathrm{CHW}$ and voucher as it will directly affect my clientele and earnings. I will be left with few clients and little earning."

Service Provider, Haripur, Khyber Pakhtunkhwa

"The poor are the main beneficiary of vouchers. The discontinuation of voucher will affect our clientele. If we stop providing free services, the ratio of clients will decrease."

Service Provider, Punjab

With respect to vouchers, some study participants cited that they will continue to work with MSS, but will charge varying prices - for example, smaller amounts from poorer clients and comparatively higher amounts from more affluent clients. Lastly, very few providers stated that quality, and not the voucher, is the key factor to increase clientele.

"Yes of course we will continue to provide family planning services even after the closure of Suraj. If clients come to us and demand the family planning services, we will provide them. Now we are providing services on voucher then we will charge them for the services."

Service Provider, Punjab
"Yes, I can work with CHW (after the project) and use my own motivator. I can fix some money for CHW as well. My suggestion is that the CHW job should be based on target and incentive. There should be no direct salary."

Service Provider, Sindh

\section{Discussion}

This study's findings reiterate the importance of engaging private providers to increase uptake of modern family planning in rural Pakistan, and further elaborates on the operational and sociocultural challenges faced by these providers. Results of this study align with the findings of past studies $(20,21)$ and provided valuable insights into the impact of social franchising on the private-sector franchised providers. The positive impact of SF on the community corresponds with existing literature (21). The study has qualitatively evaluated the 'Suraj' franchise network at the community-level; its operation, challenges, and the effect it has had on the community. The majority of participants reported satisfaction with the Suraj franchise, its objectives and the way it is currently being implemented. Findings underline the importance of combining both demandside and supply-side interventions: incorporating demand-generation elements in the demand-side intervention coupled with the supply-side intervention has benefitted both service providers and people living within the community. Moreover, training providers alleviates major supply-side barriers such as poor knowledge of FP and provider bias against LARCs (22). Another study conducted with female health workers (20) observed that female health workers faced several issues from the management, specifically the male staff, and received poor infrastructural support. CHWs faced similar transport issues, however, they generally expressed satisfaction with the support received from the management and underlined the positive impact of their work in the community.

Sustainability of SF programmes remains a challenge as the elements driving the high client volume at the clinics are elements provided or funded by the franchisor, hence it would be difficult for the providers to retain this level of volume after dissolution of the partnership. Despite the providers' willingness to serve poor women, it is difficult for them to do so without franchisor support, because of their low earnings. Providers suggested that the CHWs can potentially be retained on a pay-forperformance mechanism.

It is necessary to address the limitations of this study: firstly, study participants consisted of only providers and community health workers who were a part of the Suraj franchise network at the time of the study or who had recently dropped out. Secondly, interviewers were MSS' employees which could have biased the interviewees to exclude negative experiences with the organisation from their responses.

\section{Conclusion}

The Suraj intervention has led to a positive change in the acceptability and utilization of family planning services in 
the community. CHWs aided in raising $\mathrm{FP} / \mathrm{Rh}$ awareness in their respective communities, and vouchers played an instrumental role in getting high quality services to poorer clients through trained Suraj providers. However, there is still a need to strengthen MSS' engagement with Suraj providers to enhance their role from solely service provision to ownership of the Suraj franchise and family planning in general. This study further suggests that MSS should focus on the sustainability of this approach and explore realistic strategies for retaining resources such as $\mathrm{CHWs}$ and vouchers without MSS support. Future studies should focus on measuring these unobserved factors empirically to assess which one of these factors contributes the most to improved performance and strategize its Suraj franchise network accordingly.

\section{References}

1 National Institute of Population Studies Pakistan, Macro International Inc. Pakistan Demographic and Health Survey 2012-13. Islamabad: Government of Pakistan; 2014.

2 Sathar Z, Zaidi B. Fertility prospects in Pakistan. New York: Population Division, United Nations Department of Economic and Social Affairs; 2011.

3 Ahmed S, Khan A, Khan AA. Policy and Programme Implications of Unmet Need for Family Planning in Pakistan. J Pak Med Assoc 2013 Apr;63(4 Suppl 3):S16-S20.

4 National Institute of Population Studies Pakistan, Macro International Inc. Pakistan Demographic and Health Survey 2006-7. Islamabad: Government of Pakistan; 2008 Jun.

5 World Health Organization. From Evidence to Policy: Expanding Access to Family Planning Optimizing the health workforce for effective family planning services. Geneva: World Health Organization; 2012.

6 Department of Reproductive Health and Research. Public policy and franchising reproductive health: current evidence and future directions. 2007. Geneva, World Health Organization.

Ref Type: Online Source Montagu D, Goodman C, Berman P, Penn A, Visconti $A$. Recent trends in working with the private sector to improve basic healthcare: a review of evidence and interventions. Health Policy Plan 2016 Oct 1;31(8):1117-32. World Health Organization. Public policy and franchising reproductive health: current evidence and future directions Guidance from a technical consultation meeting. Geneva: World Health Organization; 2007.

9 Stephenson R, Tsui AO, Sulzbach S, Bardsley P, Bekele G, Giday T, et al. Franchising Reproductive Health Services. Health Serv Res 2004 Dec 1;39(6p2):2053-80.
Bellows B, Bulaya C, Inambwae S, Lissner CL, Ali M, Bajracharya A. Family Planning Vouchers in Low and Middle Income Countries: A Systematic Review. Stud Fam Plann 2016 Nov 1;47(4):357-70.

11 Gul, X., Siddiqui, J., Nasar, A., Shaikh, F., Gardezi, L., \& Balal, A. (2016). Social franchising of family planning services for improving clinical quality of family planning services and increasing client volumes at privately owned clinics: Evidence from the Suraj social franchise network, Pakistan, 2013-2014. In K. Longfield, D. Montagu, A. Sprockett \& S. Leisher, Quality Measurement in Family Planning: Past, Present, Future: Papers from the Bellagio meeting on Family Planning Quality, October 2015. (1st ed.). Oakland, CA: Metrics for Management.

Shelton JD. The Provider Perspective: Human After All. Int Fam Plan Perspect 2001;27(3):15261.

13 Khan A, Shaikh BT. An all time low utilization of intrauterine contraceptive device as a birth spacing method- a qualitative descriptive study in district Rawalpindi, Pakistan. Reprod Health 2013;10(1):10.

14 Mugisha JF, Reynolds H. Provider perspectives on barriers to family planning quality in Uganda: a qualitative study. Journal of Family and Reproductive Health 2008;34(1):37-41.

15 Bongaarts J, Bruce J. The Causes of Unmet Need for Contraception and the Social Content of Services. Stud Fam Plann 1995 Mar 1;26(2):57-75.

16 Azmat SK, Shaikh BT, Hameed W, Mustafa G, Hussain W, Asghar J, et al. Impact of Social Franchising on Contraceptive Use When Complemented by Vouchers: A QuasiExperimental Study in Rural Pakistan. PLoS ONE 2013 Sep 12;8(9):e74260.

17 Azmat SK, Hameed W, Hamza HB, Mustafa G, Ishaque M, Abbas $G$, et al. Engaging with community-based public and private mid-level providers for promoting the use of modern contraceptive methods in rural Pakistan: results from two innovative birth spacing interventions. Reprod Health 2016 Mar;13(1):1-15.

18 Azmat S, Shaikh B, Hameed W, Bilgrami M, Mustafa G, Ali M, et al. Rates of IUCD discontinuation and its associated factors among the clients of a social franchising network in Pakistan. BMC Women's Health 2012;12(1):8.

19 Hameed W, Azmat S, Ishaque M, Hussain W, Munroe E, Mustafa G, et al. Continuation rates and reasons for discontinuation of intra-uterine device in three provinces of Pakistan: results of a 24-month prospective client follow-up. Health Research Policy and Systems 2015;13(Suppl 
20 Azmat SK, Mustafa G, Hameed W, Asghar J, Ahmed A, Shaikh BT. Social Franchising and Vouchers to Promote Long-Term Methods of Family Planning in Rural Pakistan:A Qualitative Stocktaking with Stakeholders. J Pak Med Assoc 2013 Apr;63(4 Suppl. 3):S46-S53.

21 Mumtaz Z, Salway S, Waseem M, Umer N. Gender-based barriers to primary health care provision in Pakistan: the experience of female providers. Health policy and planning. 2003 Sep $1 ; 18(3): 261-9$.

22 Shelton JD. The provider perspective: human after all. International Family Planning Perspectives. 2001 Sep 1;27(3):152-61. 